\title{
PERBEDAAN FAKTOR YANG MENJADI PERTIMBANGAN MAHASISWA MEMILIH PERGURUAN TINGGI DI SURABAYA
}

\author{
Bruno Hami Pahar \\ Program Studi Manajemen \\ Fakultas Ekonomi Universitas Katolik Darma Cendika \\ Jalan Dr. Ir. H. Soekarno 201 Surabaya.
}

\begin{abstract}
This study aims to determine the differences in factors that students consider when choosing tertiary institutions in Surabaya. The population in this study were first semester students in 5 tertiary institutions namely Surabaya Institute of Technology (ITS), Widya Mandala Catholic University of Surabaya (UKWM), Surabaya University (UBAYA), Darma Cendika Catholic University (UKDC), and Petra Christian University (UKP), with a total sample of 100 students. This research was analyzed using different tests and to test the differences between three or more independent groups of two or more variables, using the Kruskal Wallis statistical method. The results showed that there were differences in factors that were considered by students to choose tertiary institutions in Surabaya, with nine factors examined, there were eight different variables among the five tertiary institutions studied, namely location (X1), reputation (X2), scholarship (X3), tuition fees (X4), entry requirements (X5), facilities (X6), number of students (X7), lecturer competencies (X8), and campus buildings (X9). The test results stated the scholarship factor (X3) there was no difference between the five tertiary institutions studied, because the H count was $7.78<H$ table $(9,488)$ and asymp. sig 0,100 > 0.05. There are differences from 8 existing factors, namely: 1) There are differences in the consideration factors of prospective students between Darma Cendika Catholic University (UKDC) with Surabaya Institute of Technology (ITS), Widya Mandala Catholic University of Surabaya (UKWM), Surabaya University (UBAYA), and Petra Christian University (UKP), namely reputation, tuition fees, entry requirements, facilities, number of students, competencies lecturers, and campus buildings, because the calculated $H$ value $>$ $H$ table $(3,841)$ and asymp. sig $<0.05$,
\end{abstract}

Keyword: consideration factor.

\begin{abstract}
ABSTRAK
Penelitian ini bertujuan untuk mengetahui adanya perbedaan faktor yang menjadi pertimbangan mahasiswa memilih perguruan tinggi di Surabaya. Populasi dalam penelitian ini adalah mahasiswa semester 1 di 5 perguruan tinggi yaitu Institut Teknologi Surabaya (ITS), Universitas Katolik Widya Mandala Surabaya
\end{abstract}


(UKWM), Universitas Surabaya (UBAYA), Universitas Katolik Darma Cendika (UKDC), dan Universitas Kristen Petra (UKP), dengan jumlah sampel sebanyak 100 mahasiswa. Penelitin ini dianalisis dengan menggunakan uji beda dan untuk menguji perbedaan antara tiga atau lebih kelompok independen dari dua atau lebih variabel, dengan menggunakan metode statistik Kruskal Wallis. Hasil penelitian menunjukan bahwa ada perbedaan faktor yang menjadi pertimbangan mahasiswa memilih perguruan tinggi di Surabaya, dengan sembilan faktor yang diteliti, ada delapan variabel yang berbeda di antara lima perguruan tinggi yang diteliti yaitu lokasi (X1), reputasi (X2), beasiswa (X3), biaya kuliah (X4), persyaratan masuk (X5), fasilitas (X6), jumlah mahasiswa (X7), kompetensi dosen (X8), dan bangunan kampus (X9). Hasil uji menyatakan faktor beasiswa (X3) tidak ada perbedaan diantara lima perguruan tinggi yang diteliti, karena $\mathrm{H}$ hitung 7,78 $<\mathrm{H}$ tabel $(9,488)$ dan asymp. sig 0,100>0,05.

Kata kunci: Faktor pertimbangan

\section{PENDAHULUAN}

Sejalan dengan pertumbuhan dan perkembangan dunia yang semakin maju dan kompetitif, terutama dalam bidang ilmu pengetahuan dan teknologi, maka setiap negara harus menyiapkan sumber daya manusianya untuk dapat menguasai ilmu pengetahuan dan teknologi secara memadai, sehingga tidak tertinggal dengan negara-negara lainnya. Untuk menghasilkan sumber daya manusia masa depan yang menguasai ilmu pengetahuan dan teknologi dengan baik, maka peranan perguruan tinggi sangat strategis. Karena di perguruan tinggi, sumber daya manusia masa depan akan dididik dan ditempa untuk menguasai berbagai ilmu pengetahuan dan teknologi.

Peran sentral dan strategis dari perguruan tinggi dalam menghasilkan sumber daya manusia yang berkualitas, sangat relevan dengan apa yang diamanatkan dalam Undang-Undang Nomor 20 Tahun 2003 tentang Sistem Pendidikan Nasional pasal 1 ayat (1) yang menyatakan bahwa pendidikan adalah usaha yang sadar dan terencana untuk mewujudkan suasana belajar dan proses pembelajaran agar peserta didik secara aktif mengembangkan potensi dirinya untuk memiliki kekuatan spriritual keagamaan, pengenalan diri, kepribadian, kecerdasan, akhlak mutu serta ketrampilan yang diperlukan dirinya, masyarakat, bangsa dan negara. Jadi perguruan tinggi merupakan ladang penyemaian untuk menghasilkan generasi terdidik yang memiliki karakter dan kepribadian bangsa yang kuat dengan kompetensi keilmuan yang mumpuni dalam bidangnya.

Untuk menghasilkan manusia yang berkualitas baik, maka diperlukan lembaga pendidikan yuang baik atau perguruan tinggi yang baik pula. Perguruan tinggi yang baik itu adalah perguruan tinggi yang mampu mengubah berbagai potensi yang dimiliki calon mahasiswa yaitu potensi mental spiritual dan intelektual. Perguruan tinggi yang berhasil dalam meningkatkan berbagai potensi tersebut pasti diperebutkan oleh calon mahasiswa, sehingga berakibat biayanya menjadi mahal. 
Ada banyak perguruan tinggi yang ada di Surabaya baik itu swasta maupun negeri. Dari jumlah perguruan tinggi yang banyak tersebut, calon mahasiswa harus memilih satu diantara yang ada. Untuk menentukan perguruan tinggi mana yang dipilih, masing-masing mahasiswa memiliki beberapa faktor pertimbangan. Penelitian ini ingin mengetahui adanya perbedaan faktor saat mahasiswa memilih perguruan tinggi yang diharapkan. Faktor-faktor yang digunakan dalam penelitian ini ada 9 yaitu: lokasi (X1), reputasi (X2), biaya kuliah (X4), persyaratan masuk (X5), fasilitas (X6), jumlah mahasiswa (X7), kompetensi dosen (X8), dan bangunan kampus (X9).

\section{TINJAUAN PUSTAKA}

\section{Pengertian Perguruan Tinggi}

Pendidikan tinggi merupakan jenjang pendidikan setelah pendidikan menengah (SMK/SMA/MA). Satuan pendidikan yang yang menyelenggarakan pendidikan tinggi disebut atau dinamai Perguruan Tinggi (PT) baik itu Perguruan Tinggi Negeri (PTN) maupun Perguruan Tinggi Swasta (PTS). Pengertian lebih jelasnya dapat dilihat dalam Undang-Undang Nomor 12 Tahun 2012 tentang Pendidikan Tinggi. Menurut pasal 1 ayat (1) Undang-Undang Nomor 12 Tahun 2012 tentang Pendidikan Tinggi pendidikan tinggi adalah jenjang pendidikan setelah pendidikan menengah yang mencakup program diploma, program sarjana, program magister, program doktor, dan program profesi, serta program spesialis yang diselenggarakan oleh Perguruan Tinggi berdasarkan kebudayaan bangsa Indonesia.

Perguruan Tinggi Negeri (PTN) adalah perguruan tinggi yang diselenggarakan oleh pemerintah. Sedangkan Perguruan Tinggi Swasta (PTS) adalah perguruan tinggi yang diselenggarakan oleh masyarakat. Pada saat ini sudah tidak ada perbedaan yang signifikan antara Perguruan Tinggi Negeri (PTN) dengan Perguruan Tinggi Swasta (PTS).

\section{Model Pengambilan Keputusan Optimasi}

Model optimasi adalah suatu model pengambilan keputusan yang menguraikan bagaimana individu-individu seharusnya berperilaku agar memaksimalkan suatu hasil. Ada enam langkah yang seharusnya seorang individu ketahui ketika akan mengambil keputusan optimasi (Robbins, 2001: 135-137), yaitu:

1. Pastikan kebutuhan akan suatu keputusan

Dasar langkah ini dituntut untuk memastikan bahwa suatu keputusan perlu diambil.

2. Kenali kriteria keputusan

Jika seseorang sudah memastikan adanya kebutuhan untuk pengambilan keputusan, maka kriteria dalam pengambilan keputusan tersebut sudah harus diketahui.

3. Alokasikan bobot kepada kriteria tersebut

Kriteria yang sudah ditentukan diberi bobot untuk memprioritaskan pentingnya dalam pengambilan keputusan. 
4. Kembangkan alternatif-alternatif

Pengambil keputusan mendaftarkan semua alternatif yang lulus penilaian.

5. Evaluasi alternatif-alternatif itu

Setelah alternatif dikenali pengambil keputusan harap segera untuk mengevaluasi satu persatu secara teliti. Kekuatan dan kelemahan dari setiap alternatif akan menjadi pembeda jika alternatif tersebut dibandingkan terhadap kriteria dan bobot yang ditetapkan. Evaluasi dari setiap alternatif dapat dilakukan dengan menilainya terhadap kriteria yang dibobot.

6. Pilih alternatif terbaik

Memilih alternatif terbaik dari antara alternatif-alternatif yang sudah dinilai terbaik diberikan skor paling tinggi.

\section{Faktor - Faktor Pengambilan Keputusan}

Menurut Miller dalam Murtono (2009) pengambilan suatu keputusan individu dipengaruhi oleh tiga faktor utama yaitu:

1. Nilai individu

Nilai individu pengambil keputusan merupakan keyakinan dasar yang digunakan seseorang jika ia dihadapkan pada permasalahan dan harus mengambil suatu keputusan. Nilai-nilai ini telah tertanam sejak kecil melalui suatu proses belajar dari lingkungan keluarga dan masyarakat. Dalam banyak keadaan, individu bahkan tidak berfikir untuk menyusun atau menilai keburukan dan lebih ditarik oleh kesempatan untuk menang.

2. Kepribadian

Keputusan yang diambil seseorang juga dipengaruhi oleh faktor psikologis seperti kepribadian. Dua variable utama kepribadian yang berpengaruh terhadap keputusan yang dibuat, seperti ideologi versus kekuasaan dan emosional versus obyektivitas. Beberapa pengambil keputusan memiliki suatu orientassi ideologi tertentu yang berarti keputusan dipengaruhi oleh suatu filosofi atau suatu perangkat prinsip tertentu.

3. Kecenderungan dalam pengambilan risiko

Meningkatkan kecakapan dalam membuat keputusan, harus dapat membedakan situasi ketidakpastian dari situasi risiko, karena keputusan yang berbeda dibutuhkan dalam kedua situasi tersebut. Ketidakpastian adalah kurangnya pengetahuan hasil tindakan, sedangkan risiko adalah kurangnya kendali atas hasil tindakan dan menganggap bahwa si pengambil keputusan memiliki pengetahuan hasil tindakan walaupun ia tidak dapat mengendalikannya.

\section{HIPOTESIS PENELITIAN}

Hipotesis yang diajukan dalam penelitian ini adalah sebagai berikut:

H1: Ada perbedaan lokasi, reputasi, beasiswa, biaya kuliah, persyaratan masuk, fasilitas, jumlah mahasiswa, kompetensi dosen, dan bangunan kampus antara Institut Teknologi Surabaya (ITS), Universitas Katolik Widya Mandala Surabaya (UKWM), Universitas Surabaya (UBAYA), Universitas Katolik Darma Cendika (UKDC), dan Universitas Kristen Petra (UKP). 


\section{METODE PENELITIAN \\ Identifikasi Variabel}

Variabel yang digunakan dalam penelitian ini terdiri dari variabel bebas (independen) dan variabel terikat (dependen). Variabel bebas (independen) terdiri dari: lokasi (X1), reputasi (X2), beasiswa (X3), biaya kuliah (X4), persyaratan masuk (X5), fasilitas (X6), jumlah mahasiswa (X7), kompetensi dosen (X8), dan bangunan kampus (X9). Sedangkan variabel terikat (dependen) yaitu keputusan memilih perguruan tinggi $(\mathrm{Y})$.

\section{Teknik Pengukuran Data}

Data yang digunakan dalam penelitian ini akan diukur dengan menggunakan skala Likert yaitu skala yang digunakan untuk mengukur sikap dengan menyatakan setuju dan tidak setuju terhadap suatu subjek/objek atau kejadian tertentu. Setiap pertanyaan akan diukur dengan menggunakan lima skala yang komposisi bobotnya sebagai berikut: Sangat Tidak Setuju (STS), Tidak Setuju (TS), Normal (N), Setuju (S), dan Sangat Setuju (SS).

\section{Sumber Data}

Sumber data yang digunakan adalah data yang diperoleh secara langsung dari sumber yaitu responden, melalui penyebaran kuisioner dibagi kepada mahasiswa semester 1 pada 5 perguruan tinggi di Surabaya, yaitu Institut Teknologi Surabaya (ITS), Universitas Katolik Widya Mandala Surabaya (UKWM), Universitas Surabaya (UBAYA), Universitas Katolik Darma Cendika (UKDC), dan Universitas Kristen Petra (UKP).

\section{Populasi dan sampel}

Yang menjadi populasi dalam penelitian ini adalah mahasiswa semester 1 di Institut Teknologi Surabaya (ITS), Universitas Katolik Widya Mandala Surabaya (UKWM), Universitas Surabaya (UBAYA), Universitas Katolik Darma Cendika (UKDC), dan Universitas Kristen Petra (UKP).

Untuk menentukan jumlah sampel dalam penelitian ini digunakan teknik random sampling (Indrianto dan Supomo, 1999: 125), di mana setiap populasi diberi kesempatan yang sama bersifat tak terbatas untuk dipilih sebagai sampel. Menurut Roscoe dalam Sugiyono (2014: 164) ukuran sampel yang layak dalam penelitian adalah 30 sampai 500. Berdasarkan pendapat tersebut, maka jumlah sampel dalam penelitian ini sebesar 100 responden, yang diambil dari mahasiswa semester 1, yaitu: Institut Teknologi Sepuluh Nopember (ITS) sebanyak 16 mahasiswa, Universitas Katolik Darma Cendika sebanyak 22 mahasiswa, Universitas Kristen Petra (UKP) sebanyak 21 mahasiswa, Universitas Katolik Widya Mandala (UKWM) sebanyak 20 mahasiswa, dan Universitas Surabaya (UBAYA) sebanyak 21 mahasiswa.

\section{HASIL PENELITIAN \\ Deskripsi Hasil Penelitian}

Berdasarkan jawaban responden dari kuesioner yang telah disebarkan, diperoleh hasil seperti terlihat pada Tabel 1. 
Tabel.1

Hasil Rekap Angket

\begin{tabular}{|l|c|c|c|c|c|}
\hline \multicolumn{1}{|c|}{ Faktor } & ITS & UKDC & UKWM & UKP & UBAYA \\
\hline X1= Lokasi & - & $50 \%$ & - & - & $57 \%$ \\
\hline X2= Reputasi & $75 \%$ & - & $60 \%$ & $67 \%$ & $95 \%$ \\
\hline X3= Beasiswa & $69 \%$ & $64 \%$ & $35 \%$ & $38 \%$ & $57 \%$ \\
\hline X4= Biaya Kuliah & $69 \%$ & $95 \%$ & - & - & - \\
\hline X5= Persyaratan Masuk & - & $82 \%$ & - & - & - \\
\hline X6= Fasilitas & $62,5 \%$ & - & $55 \%$ & $81 \%$ & $67 \%$ \\
\hline X7= Jumlah Mahasiswa & - & - & $70 \%$ & $86 \%$ & $71,43 \%$ \\
\hline X8= Kompetensi Dosen & $75 \%$ & - & $60 \%$ & $71,42 \%$ & $712 \%$ \\
\hline X9= Bangunan Kampus & $81 \%$ & - & $65 \%$ & $85.71 \%$ & $71,43 \%$ \\
\hline
\end{tabular}

\section{PEMBAHASAN}

Hasil angket menunjukkan bahwa lokasi (X1) merupakan pilihan bagi mahasiswa Universitas Katolik Darma Cendika (UKDC) dan Universitas Surabaya (UBAYA). Reputasi (X2) menjadi pilihan mahasiswa semua perguruan tinggi, kecuali mahasiswa Universitas Katolik Darma Cendika (UKDC) yang memilih kuliah tidak melihat faktor reputasi. Beasiswa (X3) dipilih oleh semua mahasiswa perguruan tinggi, namun mahasiswa Universitas Katolik Widya Mandala (UKWM) dan Universitas Kristen Petra (UKP) memilih faktor beasiswa dengan persentasenya yang kecil. Biaya kuliah (X4) dipilih oleh mahasiswa Institut Teknologi Surabaya (ITS) dan Universitas Katolik Darma Cendika (UKDC), karena menganggap biaya kuliah yang relatif kecil dibanding kuliah di temapat lain. Persyaratan masuk (X5) merupakan faktor yang hanya dipilih oleh mahasiswa Universitas Katolik Darma Cendika (UKDC), di mana mereka menganggap persyaratan masuk Universitas Katolik Darma Cendika (UKDC) relatif paling mudah daripada kampus lainnya. Fasilitas (X6) merupakan faktor yang dipilih oleh mahasiswa perguruang tinggi, kecuali mahasiswa Universitas Katolik Darma Cendika (UKDC) yang tidak menjadikan faktor fasilitas ketika masuk Universitas Katolik Darma Cendika (UKDC). Jumlah mahasiswa (X7) menjadi pilihan mahasiswa masuk perguruan tinggi yang dipilihnya, kecuali mahasiswa Institut Teknologi Surabaya (ITS) dan Universitas Katolik Darma Cendika (UKDC). Kompetensi dosen (X8) merupakan faktor pilihan dari mahasiswa masuk perguruan tinggi pilihannya, kecuali mahasiswa Universitas Katolik Darma Cendika (UKDC). Bangunan kampus (X9) merupakan salah satu faktor pilihan mahasiswa memilih perguruan tinggi pilihannya, kecuali mahasiswa Universitas Katolik Darma Cendika (UKDC). Faktor yang menjadi pilihan oleh 5 perguruan tinggi di Surabaya, adalah faktor beasiswa (X3), artinya tiap perguruan tinggi memberikan program beasiswa, karena beasiswa dianggap ampuh untuk menarik minat mahasiswa dalam memilih perguruan tinggi.

Perbedaan Pertimbangan faktor: lokasi (X1), reputasi (X2), beasiswa (X3), biaya kuliah (X4), persyaratan masuk (X5), fasilitas (X6), jumlah mahasiswa (X7), kompetensi dosen (X8), bangunan kampus (X9) di 5 perguruan tinggi yang diteliti, menggunakan Uji Kruskal Wallis, dengan tahap-tahap sebagai berikut: 


\section{a. Crosstabulation}

Analisis Crosstabulation adalah suatu metode analisis berbentuk tabel, di mana menampilkan tabulasi silang atau tabel kontingensi yang digunakan untuk mengidentivikasi dan mengetahui apakah ada korelasi suatu variabel dengan variabel lainnya. Yang dianalisis disini adalah hubungan antara variabel dalam baris dengan variabel dalam kolom. Hasil tabulasi silang disajikan ke dalam suatu tabel dengan variabel tersusun sebagai kolom dan baris.

b. Kruskal Wallis Test

Uji Kruskal Wallis adalah uji non parametrik berbasis peringkat yang tujuannya untuk menentukan adakah perbedaan signifikan secara statistik antara dua atau lebih kelompok variabel independen pada variabel dependen yang berskala data numerik (interval/rasio) dan skala ordinat. Uji ini identik dengan uji One Way Anova pada pengujian parametris, sehingga uji ini merupakan alternatif bagi uji one way anova apabila tidak memenuhi asumsi, misalnya asumsi normalitas. Uji ini selain sebagai uji alternatif juga sebagai perluasan dari uji Mann Whitney Test, di mana uji tersebut hanya dapat digunakan pada dua kelompok variabel dependen, sedangkan Kruskal Wallis dapat digunakan pada lebih dari dua kelompok.

c. Uji Hipotesis

Pengujian Hipotesis dapat dilakukan dengan menggunakan Chi-squares dan Asymp. sig seperti dalam tabel SPSS pada Tabel.2

Tabel 2

Uji Chi-squares dan Asymp.sig

\begin{tabular}{|c|c|c|c|c|c|c|c|c|c|}
\hline \multicolumn{10}{|c|}{ Test Statistic } \\
\hline & $\mathrm{X} 1$ & $\mathrm{X} 2$ & $\mathrm{X} 3$ & $\mathrm{X} 4$ & $\mathrm{X} 5$ & $\mathrm{x} 6$ & $\mathrm{X} 7$ & $\mathrm{X} 8$ & X9 \\
\hline Chi-square & 10.535 & 37.980 & 7.780 & 41.852 & 34.070 & 31.988 & 40.648 & 11.000 & 49.801 \\
\hline Df & 4 & 4 & 4 & 4 & 4 & 4 & 4 & 4 & 4 \\
\hline $\begin{array}{l}\text { Asymp. } \\
\text { Sig. }\end{array}$ & .032 & .000 & .100 & .000 & .000 & .000 & .000 & .27 & .000 \\
\hline \multicolumn{10}{|c|}{ a. Kruskal Wallis Test } \\
\hline $\begin{array}{l}\text { b. Grouping } \\
\text { Perguruan } \\
\text { Tinggi. }\end{array}$ & Variable: & & & & & & & & \\
\hline
\end{tabular}

Tabel 2 menunjukan bahwa $\mathrm{H}$ tabel untuk $\mathrm{df}=4$ dengan tingkat kepercayaan $95 \%$ $(\alpha=0,05)$ adalah 9,488 dan untuk $\mathrm{H}$ hitung lokasi (X1), reputasi (X2), biaya kuliah (X4), persyaratan masuk (X5), fasilitas (X6), jumlah mahasiswa (X7), kompetensi dosen (X8), bangunan kampus (X9) yang nilai Chi-Square $>9,488$, maka keputusannya $\mathrm{H} 0$ ditolak dan $\mathrm{H} 1$ diterima, artinya ada perbedaan faktorfaktor tersebut di antara 5 perguruan tinggi yang diteliti. Sedangkan beasiswa (X3) nilai $\mathrm{H}$ hitungnya 7,78 $<9,488(\mathrm{H}$ tabel), dan nilai Asymp. sig $=0,100>$ 0,05, maka keputusanya H0 diterima, sehingga untuk beasiswa (X3) tidak ada perbedaan diantara 5 perguruan tinggi yang diteliti. Fakta ini mengungkapkan bahwa beasiswa yang diberikan pada semua perguruan tinggi tidak jauh bebeda, 
semuanya dianggap sama bagi mahasiswa untuk masuk ke Institut Teknologi Surabaya (ITS), Universitas Katolik Widya Mandala (UKWM), Universitas Kristen Petra (UKP), Universitas Katolik Darma Cendika (UKDC), dan Universitas Surabaya (UBAYA). Mahasiswa memilih perguruan tinggi bukan karena beasiswa yang diberikan, melainkan faktor lainnya yang dianggap lebih menarik.

\section{SIMPULAN}

Dari 9 faktor yang menjadi dasar mahasiswa memilih perguruan tinggi, ada 8 faktor yang berbeda dalam mahasiswa mempertimbangkan memilih perguruan tinggi di Surabaya, yaitu lokasi, reputasi, biaya kuliah, persyaratan masuk, fasilitas, jumlah mahasiswa, kompetensi dosen, dan bangunan kampus. Sedangkan 1 faktor lainnya yaitu beasiswa menunjukkan tidak ada perbedaan faktor yang menjadi pertimbangan mahasiswa dalam memilih perguruan tinggi di Surabaya.

Ditinjau dari semua faktor yang menjadi dasar pilihan mahasiswa memilih perguruan tinggi di Surabaya, masing-masing perguruan tinggi memiliki keunggulan pilihan yang berbeda-beda. Untuk Institut Teknologi Surabaya (ITS) faktor utama mahasiswa memilih perguruan tinggi adalah bangunan kampus. Bagi Universitas Katolik Darma Cendika, faktor yang paling dipertimbangkan mahasiswa adalah biaya kuliah. Sedangkan untuk Universitas Katolik Widya Mandala (UKWM) dan Universitas Kristen Petra (UKP) faktor yang paling dipertimbangkan adalah jumlah mahasiswa. Kemudian untuk Universitas Surabaya (UBAYA) faktor reputasi yang menjadi pilihan utama mahasiswa.

\section{SARAN}

Untuk Institut Teknologi Surabaya (ITS) faktor yang paling dominan mahasiswa memilih perguruan tinggi adalah bangunan kampus. Karena itu disarankan agar bangunan kampus di Institut Teknologi Surabaya (ITS) lebih dipelihara dan terus dikembangkan, karena mahasiswa memilih kuliah di Institut Teknologi Surabaya (ITS) prioritasnya adalah bangunan kampusnya. Untuk Universitas Katolik Darma Cendika (UKDC), disarankan agar biaya kuliah dapat dipertahankan, karena mahasiswa memilih kuliah di Universitas Katolik Darma Cendika (UKDC) prioritas utamanya adalah faktor biaya kuliah yang relatif murah dibanding perguruan tinggi lainnya. Bagi Universitas Katolik Widya Mandala (UKWM) dan Universitas Kristen Petra (UKP) disarankan menjaga kualitas lulusan mahasiswa, agar mahasiswa yang masuk jumlahnya banyak. Hal ini merupakan salah satu faktor paling besar yang dipilih mahasiswa untuk kuliah di Universitas Katolik Widya Mandala (UKWM) dan Universitas Kristen Petra (UKP). Sedangkan untuk Universitas Surabaya (UBAYA) yang memiliki faktor reputasi paling besar yang dipilih oleh mahasiswa kuliah di Universitas Surabaya (UBAYA), harus tetap menjaga reputasi tersebut dengan cara memperluas jaringan kerjasama.

\section{DAFTAR PUSTAKA}

Arifin, Johar, 2017, SPSS 24 untuk Penelitian dan Skripsi, Penerbit Elex Media Komputindo, Jakarta. 
Djaali, H., 2009, Psikologi Pendidikan, Bumiaksara, Jakarta.

Engel, James F, Roger D Blackwell, dan Paul W Miniard, 2001, Perilaku Konsumen, Binarupa Aksara, Jakarta.

Ghozali, H. Imam, 2000, Aplikasi Analisis Multivariate dengan Program SPSS, Cetakan Keempat, Badan Penerbit Universitas Diponegoro, Semarang.

Indriantoro, Nur dan Bambang Supomo, 1999, Metodologi Penelitian Bisnis, untuk Akuntansi dan Manajemen, Edisi Pertama, BPFE UGM, Yogyakarta.

Kotler, Philip, 2000, Prinsip-Prinsip Pemasaran Manajemen, Prenhalindo, Jakarta.

Kotler, Philip dan Gary Armstrong, 2001, Dasar-Dasar Pemasaran, Jilid I, Alih Bahasa Oleh Alexander Sindoro, Indeks Kelompok Gramedia, Jakarta.

Kotler, Philip, 2005, Manajemen Pemasaran, Edisi 11, Jilid 2, Prenhalindo, Jakarta.

Mangkunegara, Anwar Prabu, 2005, Perilaku Konsumen, Edisi Revisi, Refika Aditama, Bandung.

Murtono, Imam, 2009, Pengambilan Keputusan dalam Organisasi, diakses dari http://Scolar.geogle.co.id/07/Pengambilan Keputusan Dalam Organisasi.

Noor, Juliansyah, 2014, Analisis Data Penelitian Ekonomi dan Manajemen, Cetakan Pertama, Grasindo, Jakarta.

Prasetyo, Ristiyanti dan John J. O. Ihalauw, 2005, Perilaku Konsumen, Andi Offset,Yogyakarta.

Robbins, Stephen P., 2001, Perilaku Organisasi: Konsep, Kontroversi, Aplikasi, Jilid I, Edisi 8, Prenhallindo, Jakarta.

Shiffman, Leon dan Leslie Lazar Kanuk, 2007, Perilaku Konsumen, Edisi Ke Tujuh, Indeks, Jakarta.

Sugiyono, 2014, Metode Penelitian Manajemen, Cetakan Ketiga, Alfabeta, Bandung.

Suryani, Tatik, 2008, Perilaku Konsumen: Implikasi pada Strategi Pemasaran, Edisi Pertama, Graha Ilmu, Yogyakarta.

Undang-Undang Nomor 20 Tahun 2003 tentang Sistem Pendidikan Nasional.

Undang-Undang Nomor 12 Tahun 2012 tentang Pendidikan Tinggi. 